\title{
STUDY ON CYCLOSPORA CAYETANENSIS IN KATHMANDU VALLEY
}

\author{
Gupta $R^{*}$, Gurung $R^{* *}$, Sherchand J B** Jha S C*
}

\section{ABSTRACT}

Cyclospora caytanensis, a human pathogenic coccidian parasite owes its recognition as an emerging parasite, which continues to be found throughout the world. Its prevalence was investigated in Kathmandu valley, Nepal in 2003. Stool examination was performed with a total of 500 specimens from 3 Hospitals, 1 Geriatric Centre (Briddhaashram), 1 Infectious and Tropical Disease Research Center/Nepal and 8 Slum areas by direct smear technique. Out of these specimens, Cyclospora caytenensis oocysts were found in $7 \%$ of specimens with the age range from 2 months to 67 years. To identify possible sources for Cyclospora infection, water samples from 3 rivers, 134 fecael samples of animals and 43 samples of green leafy vegetables wash were collected and examined by formal-ether sedimentation and floatation technique. As a result, oocyst of Cyclospora was identified only in chicken stool sample, which could be possible reservoir host for Cyclospora infection. However, further studies are needed to shed light on possible sources of infection.

Key Words: Cyclospora caytanensis, coccidian parasite, diarrhoea, faecal specimens.

\section{INTRODUCTION}

An elusive pathogenic protozoan parasite that has gained attention of whole world is Cyclospora cayetanensis, which was first described in $1979 .{ }^{1}$ Before 1995 , this coccidian parasite was primarily reported as a cause of gastroenteritis among children living in poor sanitary conditions ${ }^{2,3}$ and adults from industrialized countries who lived or travelled in developing countries.,5,6 More recent reports are from North, Central \& South America, the Caribbean, England, Wastern Europe, Africa, the Indian subcontinent, Southeast Asia and Australia. ${ }^{7}$ The most highly endemic areas are Peru, ${ }^{8}$ Haiti ${ }^{9}$ and Nepal. ${ }^{4,10}$

Cyclospora oocysts measure $8 \mu \mathrm{m}$ to $10 \mu \mathrm{m}$ in diameter and stain variably acidfast. Without the use of an ocular micrometer, oocysts of Cyclospora might be easily confused with those of Cryptosporidium. Oocysts are easily observed by phase contrast microscopy and the algal-like morula appearance is evident in fresh stool. A useful and distinguishing feature is oocyst autofluorescence. The life cycle of $C$. cayetanensis begins, like all enteric coccidia with ingestion of sporulated "oocyst" which consists of 2 "sporocysts" and each enclosing 2 "sporozoities". Inside the gut, sporozoites exit from sporocysts and penetrate epithelial cells. The preferred site is jejunum and proceeds the cycle of schizogony and gametogeny. Hence both sexual and asexual stages are completed in a single host. Further sporogony and sporulation occur exogeniously. ${ }^{11}$

Individual infected with Cyclospora may experience prolonged watery diarrhoea, abdominal cramping, weight loss, anorexia,

* Tribhuvan University, Kirtipur, Kathmandu, Nepal.

** Tri-Chandra Multiple Campus, Ghantaghar, Kathmandu, Nepal.

*** Tribhuvan University Teaching Hospital, Institute of Medicine, Maharajgunj, Kathmandu, Nepal.

Address for correspondence : Dr. Ranjana Gupta

Tribhuvan University, Kirtipur, Kathmandu, Nepal.

Email: rgupta_ohm@yahoo.co.in 
myalgia, and occasionally vomiting. Symptoms generally begin approximately one week after ingestion of oocysts and these may persist for a month or more. The small intestine becomes inflamed and the parasite causes mucosal changes that include villous atropy and crypt hyperplasia. Success treatment has been achieved by co-trimoxazole (160 mg trimethoprim, 800 mg sulpamethoxazole).

The first known outbreak of cyclosporiasis in the US occurred in 1990 in a Chicago hospital's physicians' dormitory and was attributed to an infected water source. ${ }^{12}$ The study conducted in $\mathrm{Nepal}^{13}$ also strongly suggested water borne transmission of Cyclospora. Food borne transmission was first suggested in 1995 when the food prepared in a Haitian kitchen was brought in the airplanes. ${ }^{14}$ The US epidemics of cyclosporiasis were attributed to infected Guatemalan raspberries, basil and mesclum lettuce. ${ }^{15}$ Cyclospora oocysts have been isolated from vegetables from a disease-endemic area of Lima, Peru and Nepal. ${ }^{16,17}$ In addition to human, Cyclospora like oocyst has been reported from moles, baboons, chimpanzees, chicken, dogs and rats..$^{10,18,19,20,21}$ But the issue of potential animal host for Cyclospora has not been completely resolved. Hence the study was carried out to determine the prevalence of Cyclospora infection in Kathmandu valley and possible sources of infection.

\section{MATERIALS AND METHODS}

A study was conducted between May to October, 2003. A total of 500 stool samples were collected in which 84 from Kanti Children's Hospital (Oral Rehydration Therapy Ward), 63 from Tribhuvan University Teaching Hospital (Pathology Laboratory), 102 from Sukra Raj Tropical and Infectious Hospital (Gastrointestinal Ward), 30 from Infectious and Tropical disease
Research center, 40 from Geriatric Centre (Bridhhaashram) and 181 from Sukumabasi tole of Kathmandu. Before collection of samples following information were recorded such as age, sex, month, clinical symptoms, physical characteristic of stool and drinking water as well as food habit amongst people. These collected samples were examined within $4-8$ hours of passage in normal saline by direct light microscopy at $400 \mathrm{X}$ and those samples, which were not abled to examine on same day, were preserved in $2.5 \%$ potassium dichromate. In addition, animals, vegetables and river water samples were also collected to determine the mean of transmission. A total of 134 stool samples were collected from different animals such as dog, horse, cow, buffalo, duck, chicken, monkey, crow, mouse and cat. These collected samples were examined by formalin-ether concentration method.

From June to August 2003, 49 samples of vegetables were collected from local market of Bahaktapur, Kalimati, Sastobazar in Patan and Khasibajar in Baghbazar. In vegetable samples coriander leaf, spinach, lettuce, mustard leaf, green onion, cabbage, green garlic leaf, radish, carrot, pumpkin leaf, cauliflower and other green leafy vegetables were included. While water samples (rivers) were collected from Bishnumati, Bagmati and Hanumantekhola in which 3 samples were collected from different sites of each river. The vegetables were washed in distilled water; the washing and the sample of water were centrifuged to examine the sediment microscopically.

All the positive and suspected samples of stool, river-water and leafy vegetable were preserved in $2.5 \%$ of potassium dichromate at room temperature $\left(29^{\circ} \mathrm{C}\right)$ for 2 weeks for sporulation. These samples were also confirmed by modified acid fast staining method. The samples were fixed with methanol and stained with carbolfuchsin. The presences of

Table I : Age-wise Prevalence of Cyclospora Infection

\begin{tabular}{cc|c|c}
\hline $\begin{array}{c}\text { Age Group } \\
\text { (Years) }\end{array}$ & $\begin{array}{c}\text { Total Number of } \\
\text { samples examined }\end{array}$ & $\begin{array}{c}\text { Number of } \\
\text { positive samples }\end{array}$ & $\%$ \\
\hline $0-10$ & 134 & 18 & 13.4 \\
\hline $10-20$ & 89 & 5 & 5.6 \\
\hline $20-30$ & 84 & 3 & 3.6 \\
\hline $30-40$ & 65 & 3 & 4.6 \\
\hline $40-50$ & 26 & 2 & 7.7 \\
\hline $50-60$ & 34 & 3 & 8.8 \\
\hline $60-70$ & 35 & 1 & 2.9 \\
\hline $70-80$ & 22 & 0 & 0 \\
\hline $80-90$ & 10 & 0 & 0 \\
\hline $90-100$ & 1 & 0 & 0 \\
\hline Total & $\mathbf{5 0 0}$ & $\mathbf{3 5}$ & $\mathbf{7 . 0}$ \\
\hline
\end{tabular}

Sex-wise : $?^{2}=0.142, P$ ? 0.05, Age-wise $: ?^{2}=12.45, P>0.05$

(not significant)

(significant) 
Table II : Site-wise Prevalence of Cyclospora Infection

\begin{tabular}{l|cc|c}
\hline \multicolumn{1}{c|}{ Sites } & $\begin{array}{c}\text { Total no. of } \\
\text { samples }\end{array}$ & $\begin{array}{c}\text { No. of } \\
\text { positive cases }\end{array}$ & \% \\
\hline Briddhashram & 40 & 0 & 0 \\
\hline Teaching Hospital & 63 & 2 & 3.2 \\
\hline Kanti Children's Hospital & 84 & 6 & 7.1 \\
\hline Sukra Raj Tropical \& Infectious Hospital & 102 & 5 & 4.9 \\
\hline Infectious \& Tropical Disease & 30 & 8 & 26.7 \\
Research Centre/Nepal (ITDRC) & & & \\
Slum Areas $\quad$ Total & 181 & 14 & 7.7 \\
& $\mathbf{5 0 0}$ & $\mathbf{3 5}$ & $\mathbf{7 . 0}$
\end{tabular}

Table III : Distribution of Clinical Symptoms in Cyclospora cayetanensis Positive Patients

\begin{tabular}{l|c|c}
\hline \multicolumn{1}{c|}{ Clinical Symptoms } & No. of Positive Cases & \% \\
\hline Constipation & 2 & 5.7 \\
\hline Fatigue & 12 & 34.3 \\
\hline Anorexia & 13 & 37.1 \\
\hline Myalgia & 5 & 14.3 \\
\hline Abdominal cramps & 14 & 40.0 \\
\hline Flatulence & 6 & 17.1 \\
\hline Dyspepsia & 9 & 25.7 \\
\hline Nausea & 12 & 34.3 \\
\hline Vomiting & 6 & 17.1 \\
\hline Fever & 8 & 22.9 \\
\hline Weight Loss & 7 & 20.0 \\
\hline Allergy & 1 & 2.9 \\
\hline
\end{tabular}

Table IV : Study of Cyclospora in Various Animals

\begin{tabular}{lc|c|c}
\hline \multicolumn{1}{c|}{ Animals } & $\begin{array}{c}\text { Total No. of } \\
\text { Samples }\end{array}$ & $\begin{array}{c}\text { Number of } \\
\text { Positive Cases }\end{array}$ & \% \\
\hline Dog & 20 & 0 & 0 \\
\hline Horse & 20 & 0 & 0 \\
\hline Cow & 12 & 0 & 0 \\
\hline Buffalo & 15 & 0 & 0 \\
\hline Duck & 8 & 0 & 0 \\
\hline Chicken & 23 & 1 & 0.3 \\
\hline Monkey & 23 & 0 & 0 \\
\hline Crow & 1 & 0 & 0 \\
\hline Mouse & 10 & 0 & 0 \\
\hline Cat & 2 & 0 & 0 \\
\hline \multicolumn{1}{r|}{ Total } & $\mathbf{1 3 4}$ & $\mathbf{1}$ & $\mathbf{1 . 6}$ \\
\hline
\end{tabular}

other protozoan and helminth eggs were also recorded.

\section{RESULTS}

Of 500 human stool specimens, 35(7\%) were found to be positive for C. cayetanensis. Of the 35 persons, 17(7.1\%) were males and 18(6.9\%) were females with age range from 2 months to 67 years. As regards age-wise prevalence of Cyclospora (Table I) it was found that the highest prevalence $(13.4 \%)$ was in the children below 10 years of age. None of the samples above 70 years was found to be positive for Cyclospora.
Regarding site-wise infection, the prevalence of Cyclospora infection was found to be nil in Bridhhashram (Table II) whereas the highest infection rate was found in ITDRC $(26.7 \%)$, followed by slum areas $(7.7 \%)$.

Month-wise prevalence of Cyclospora (Fig.1) showed significant difference in different months. There was a rise in infection rate from May (3.6\%) to July (12.09\%) and then it gradually decreased till October $(3.8 \%)$.

The most common enteric symptom amongst the Cyclospora positive cases was diarrhoea $(48.6 \%), 40 \%$ of cases were 


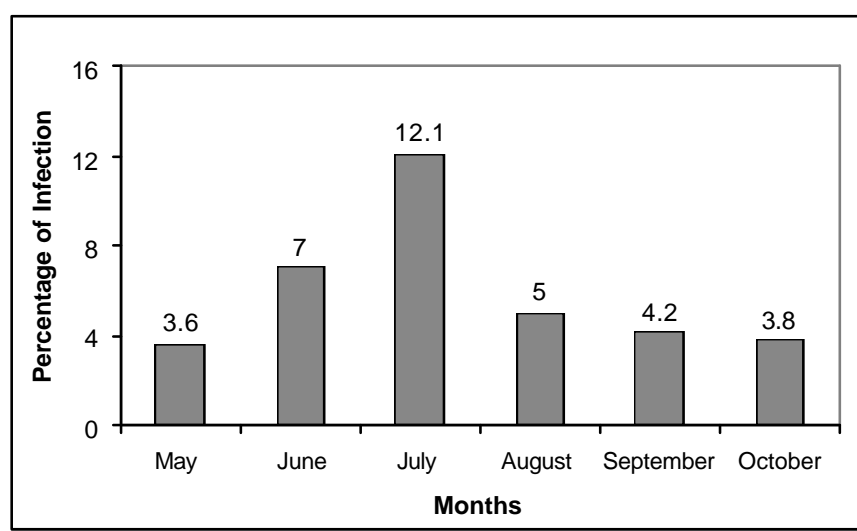

Fig. 1 : PR \& NCDR Trend of Nepal

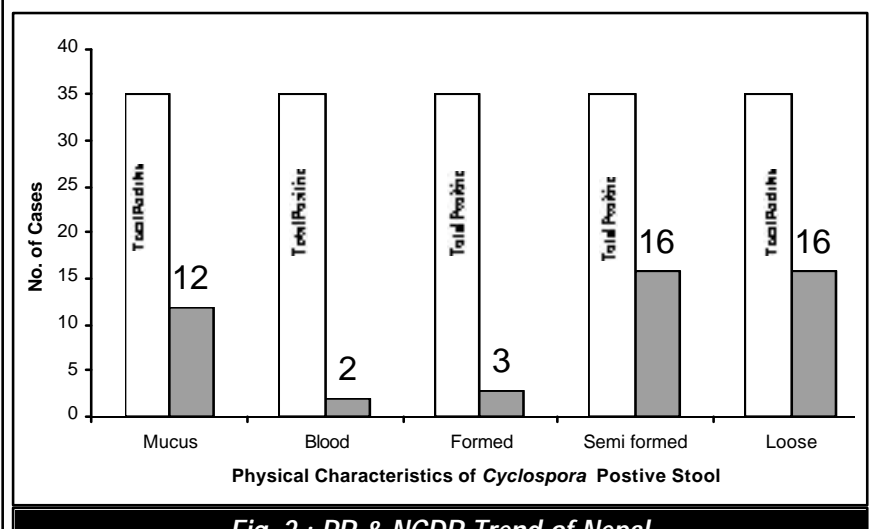

Fig. 2 : PR \& NCDR Trend of Nepal

without diarrhoea but with one or more other symptoms as given in Table III and $11.4 \%$ were asymptomatic.

\section{Drinking water and food habit amongst people infected with cyclospora}

Among the Positive cases, 20(57.1\%) were found to consume unboiled and unfiltered water. Only $8(22.9 \%)$ used boiled and $7(20 \%)$ used filtered or halogenated treated water. Vegetables and fruits were found to be ingested raw or undercooked by washing in direct tap water, well water and dhunge-dhara.

\section{Co-infection of cyclospora with other intestinal parasites}

Out of 35 positive cases, 34.3\%(12) showed coinfection with one or more other intestinal parasites: Trichuris trichiura(3), Ascaris lumbricoides(3), Entamoeba histolytica(1), Giardia intestinalis(2), Hymennolepis nana(1), Hook worm(1) and Cryptosporidium(2).

\section{Study of cyclospora like oocysts in various animals}

Of 134 faecal samples of different animal's examined for the prevalence of Cyclosopra oocysts only 1 sample of chicken was found to be positive (Table IV).
Study of vegetable - washes and river - water samples to detect cyclospora oocysts

49 samples of different vegetable washes and 9 river water samples were examined for detection of Cyclospora oocysts. Although some eggs, oocysts and larvae of identified and unidentified parasites had been detected but none of the samples were found to be positive for Cyclospora oocyst.

\section{DISCUSSION}

Cyclospora cayetanensis has emerged as a dominant protozoan parasite since the past decade in Nepal. Although all age groups can acquire this parasite, the infection was found in children older than 18 months. ${ }^{2}$ However, this study showed the infection in the 2 months children also and is supported by Sherchand et al. ${ }^{17,22}$ This study showed the infection rate with Cyclospora to be the highest in the children below 10 years. Similar results were obtained by Caryn et al. ${ }^{23}$ and Sherchand and Cross. ${ }^{24}$

Regarding sex-wise, in this study there was no significant difference of infection among male and female and is also reported by Caryn et al. ${ }^{23}$ But Amin ${ }^{25}$ reported positive cases more in females than males.

In the present study the prevelance of Cyclospora was the highest in Infectious and Tropical Disease Research Centre, Nepal as it is one of the referral center for diagnosis of pathogenic parasite followed by Sukumbasi tole due to unhygienic condition. The infection rate in oral rehydration therapy ward of Kanti Children's Hospital \& gastrointestinal ward of Sukra Raj Tropical and Infectious Hospital was found more than pathological laboratory of Tribhuvan University Teaching Hospital as from this pathological laboratory samples were also collected from those patients who had not any gastrointestinal problem. The infection rate with Cyclospora in Briddhashram was nil which goes with the age-wise prevalence rate which showed old people are not so much susceptible with Cyclospora. ${ }^{4}$ But Conner et al. reported that there is no apparent immunity to infection, and reinfection can occur at all ages.

The highest rate of infection occured in warm rainy season i.e. July and is supported by Hoge et al. ${ }^{4}$ and Sherchand and Cross..$^{10}$ But dissimilar to Ortega et al.(1997) in which peak rate in Peru occured in warm dry season. 
The most common clinical symptom in Cyclospora infection was diarrhoea $\&$ is supported by Huang et al. ${ }^{12}$ and Amin..$^{25}$ In $40 \%$ of cases the oocysts occurred in absence of watery diarrhoea $\&$ is supported by Eberhard et al., ${ }^{26}$ Sherchand and Cross. ${ }^{24}$ And in $11.4 \%$ of cases the disease occurred asymptomatically and is also reported in other studies..$^{23,24}$

There may be relationship between occurrence of concurrent parasite i.e. one or more parasite with Cyclospora which in the present study was found $34.3 \%$. Amin found the pathogens like E. histolytica and G. intestinalis reduce the immunity, which may result the host to be more susceptible to new infection. ${ }^{25}$ Sherchand et al. also reported that immune compromised patients to be more susceptible to parasitic infection than the immune competent. ${ }^{27}$

In the present study, the Cyclopora like oocyst was found in the fecael sample of chicken, which has diagnostic features of C. cayetanensis. The possibility that the oocyst may have acquired by chicken as contamination by food or water sources were only passing through their gut (making chicken as paratonic host) cannot be ruled out. Beside chicken, also reported the presence of Cyclospora oocysts in chicken, dog, rat etc. But the issue of potential animal hosts for Cyclospora and the possibility of human infection by this protozoan being a zoonosis are not clear. ${ }^{10,20,21,28}$

In the present study the oocyst was neither found in vegetable washes nor in river water samples. This may be due to the fact that the simple washing of vegetable does not remove the Cyclospora oocyst easily and also due to small river sample size.

Although the Cyclospora transmission is not fully known, however water and contaminated food might be the major source of infection. The main causes of contamination of water are seepage into water supply pipes and discharging of sewage and other pollutant into rivers from where the water is carried to the vegetable fields for irrigation and the vegetables are easily contaminated which provide suitable environment for the oocyst survival for host ingestion. So further studies are needed to understand the complete biology and means of transmission of Cyclospora.

\section{REFERENCES}

1. Ashford RW. Occurrence of an Undescribed Coccidian in Man in Papua New Guinea. Ann Trop Med Parasitol. 1979; 73: 497-
500 .

2 Hoge CW, Echeverria P, Rajah R, Jacobs J, Malthouse S, Chaptman E, Jimenez IM, Shlim DR. Prevalence of Cyclospora species and Other Enteric Pathogens among Children less than 5 years of Age in Nepal. J Clin Microb. 1995; 33: 3058-3060.

3. Ortega YR, Sterling CR, Gilman RH, Cama VA, Diaz F. Cyclospora species a New Protozoan Pathogen of Human. $N$ Engl J Med. 1993; 328: 1308-1312.

4. Hoge CW, Shlim DR, Rajah R, Triplett J, Shear M, Robold JG and Echeverria P. Epidemiology of Diarmoeal illness Associated with Coccidian-like organisms among Travellers and Foreign Residents in Nepal. Lancet. 1993; 341: 1175-1179.

5. Soave R, Dubey JP, Ramos LJ and Tummings M. A New Intestinal Pathogen. Clin Res. 1986; 34: 533 abstract.

6. Wurtz R. Cyclospora: A Newly Identified Intestinal Pathogens of Human. Clin Infect Dis. 1994; 18: 620-623.

7. Sterling $C R$, Ortega $Y R$, Hartwig $E C$, Pawlowiez MB, Cook MI, Miller JR. Updata: Outbreaks of Pseudo Infection with Cyclospora and Cryptosporidium Florida and New York City, 1995. MMWR. 1997; 46: 354-358.

8. Ortega YR, Rosas CR, Gilman RH, Miler NJ, Cabrera L, Taquiri C, Sterling CR. Isolation of Cryptosporidium parvum and Cyclospora caytanensis from Vegetables Collected from Markets of an Endemic Region in Peru. Am J Trop Med Hyg. 1997; 57: 683-686.

9. Pape JW, Verdier RI, Boney M, Boney J and Johnson WD. Cyclospora infection in Adults with HIV: Clinical Manifestationis, Treatment and Prophylaxis. Ann Intern Med. 1994; 121: 654657.

10. Sherchand JB and Cross JH. Studies on Cyclospora cayetanensis Infection in Nepal. The Tenth International Congress of Parasitology. 2002; 4-9: 71-88.

11. DOB: Cyclospora cayetanensis. Update: Division of Biology, Kansas State University, Manhattan, KS 2000.

12. Huang $P$, Weber JT, Sosin DM, Griffin PM, Long EG, Murphy JJ, Kocka F, Caryn P and Charles K. The First Reported Outbreak of Diarrhoeal illness Associated with Cyclospora in United State. Ann Intern Med. 1995; 123: 409-414.

13. Rabold JG, Hoge CW, Shlim DR, Kefford C, Rajah R, Echeverria P. Cyclospora outbreak Associated with Chlorinated Drinking Water. Lancet. 1994; 344: 1360-1361.

14. Connor BA, Shlim DR. Food borne transmission of Cyclospora. Lancet. 1995; 346:1634.

15. Pritchett RG, Radke C, Moore V, Busenichner FK. Outbreak of Cyclosporiasis, Northern Virginia-Washington:DC-Baltimore, Maryland. Metroplitan Area. 1997. MMNR. 1997; 46: 689691. 
16. Ortega YR, Nagle R, Gilman RH, Watanabe J, Miyagui J, Quispe H. Pathological and Clinical Parasite Life Cycle Stages. J Infect Dis. 1997; 176: 1584-1589.

17. Sherchand JB, Cross JH, Jimba M, Sherchand S and Shrestha M. Study of Cyclospora cayetanensis in Health Care Facilities, Sewage Water and Green Leafy Vegetables in Nepal. Southeast Asian J Trop Med Public Health. 1999; 30: 58-63.

18. Ford P and Duszynski DW. Coccidian Parasites from Insectivores: VI Six New species from the Eastern Mole, Scalopus aquaticus. J Protozool. 1988; 35: 223-226.

19. Smith HV, Paton CA, Girdwood RWA, Mtambo MMA. Cyclospora in Non-human Primates. Vet Rec. 1996; 138: 528 abstract.

20. Garcia-Lopez HL, Rodriguez Tovar LE, Garza CEM-de la. Identification of Cyclospora in Poultry. Emerg Infect Dis. 1996; 2: $356-357$.

21. Yai LE, Bauab AR, Hirschfeld MP, Oliver ML de, Damkaceno JT. The First Two Cases of Cyclospora in Dogs, Sao Paulo, Brazil. Rev Int Med Trop Sao Paulo. 1997; 39: 177-179.

22. Sherchand JB, Ohara H, Sherchand S, Cross JH, Shrestha MP. Intestinal Parasitic Infection in Rural Areas of Southern
Nepal. J Inst Med. 1997; 19: 115-121

23. Caryn B, Hernanadez B, Lopez MB, Arrowood MJ, Mejia MA de, Merida AM de, Hightower AW, Venezel L, Herwaldt BL, and Klein RE. Epidemiologic Studies of Cyclospora cayetanensis in Guatemala. Emerg Infect Dis. 1999; 5: 766-773.

24. Sherchand JB and Cross JH. Emerging Pathogen Cyclospora cayetanensis Infection in Nepal. Southeast Asian J Trop Med Public Health. 2001; 32: 143-150.

25. Amin OM. Seasonal Prevalence and host relationships of Cyclospora cayetanensis in North American during 1996. Par. Int. 1998; 47: 53-58.

26. Eberhard ML, Eva KN, Amanda RF, Thomas GS, Alexandre J. Da silva and Patrick JL. Cyclospora cayetanensis in Haiti: A Common Occurrence in the Absence of Watery Diarrhoea. Am J Trop Med Hyg. 1999; 60: 584-586.

27. Sherchand JB and Cross JH. Cyclospora cayetanensis in Nepal: A study of Microbiological and Epidemiological aspects. NHRC, 2004; 3: $1-8$.

28. Sadak HAH and Malak AZ. Experiental Studies on Cyclosporiasis. J Egypt Soc Parasitol. 2001; 31: 65-77.

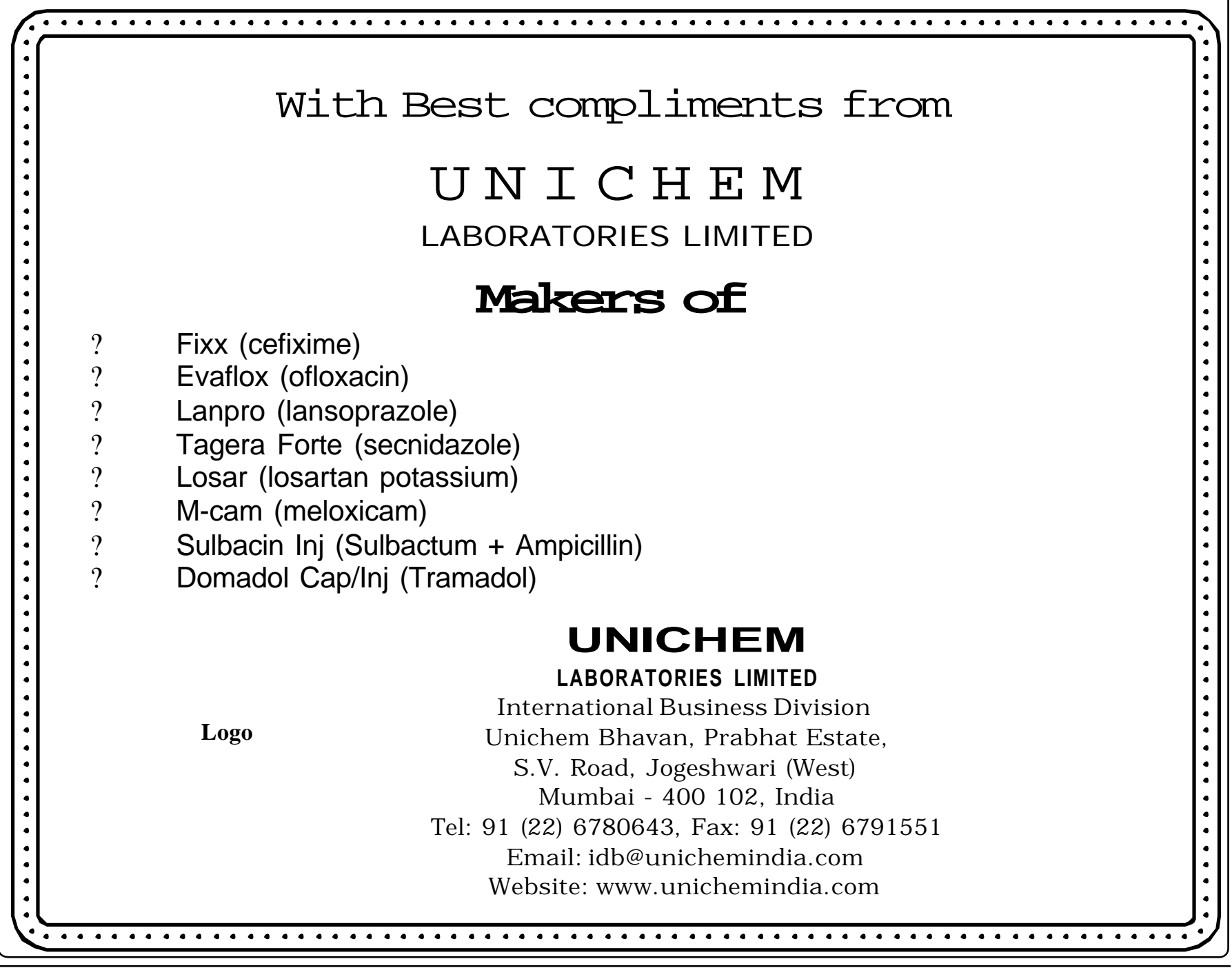

INMA Sentemher - Ortnher 20ก4 4.3 